\title{
践行课堂对话教学, 让学习真实发生
}

\section{Practice Classroom Dialogue Teaching and Make Learning Happen \\ 张兴国}

Xingguo Zhang

\section{贵州省毕节市黔西县教研室}

中国·贵州 黔西 551500

Teaching and Research Office of Qianxi County,

Bijie City, Guizhou Province,

Qianxi, Guizhou, 551500, China

贵州省 2017 中小学幼儿园教师课题式 研修省级专项课题《课堂对话教学的实 践研究》论文【2017skz002】
【摘要】课堂是教育的主阵地, 是学生获得学科知识、达成学习能力的主空间, 是学生学 科核心素养形成的主渠道。因此,课堂教学的设计、课堂教学的过程、课堂教学的反思是提 高课堂教学效率的关键。对话教学是具有时代精神的教学形态, 践行课堂对话教学能让学 生的自主探索与合作交流得以实现,达成学科核心素养的培养。

【Abstract】Classroom is the main position of education, the main space for students to obtain subject knowledge, the main space for students to achieve learning ability, and the main channel for the formation of students' core literacy of subjects. Therefore, the design of classroom teaching, the process of classroom teaching, the reflection of classroom teaching is the key to improve the efficiency of classroom teaching. Dialogue teaching is a teaching form with the spirit of the times. The practice of classroom dialogue teaching can enable students' independent exploration and cooperative communication to be realized, and achieve the cultivation of the core quality of the discipline.

【关键词】课堂对话教学; 学习真实发生

【Keywords】classroom dialogue teaching; learning reality

【DOI】10.36012/sde.v1i3.516

\section{1 引言}

对话教学是具有时代精神的教学形态, 践行课堂对话教 学能让学生的自主探索与合作交流得以实现, 达成学科核心 素养的培养 ${ }^{[1]}$ 。课堂对话教学中, 对话的主体是教师、学生和 文本, 在富有公平、批判精神的课堂氛围中, 师生依托已有知 识,以平等的沟通、交流为主要形式, 达成一种师生视界融合、 和谐共生的教学追求和教学形态。课堂教学中交互主体对话 是要深入到知识技能、思想方法的理性层次, 而不是停留在表 面的热闹讨论中 ${ }^{[2]}$, 应在相互接受和倾听的过程中, 实现精神 的相遇、视界的融合, 促使不同的意见和见解达成和谐共生的 关系, 让师生智慧和热情得到最大限度地发挥, 实现师生共同 进步 ${ }^{[3]}$ 。因此, 践行课堂对话教学是培养学生学科核心素养较 好途径。
2 基于对话的课堂教学设计(表 1)

表 1 课堂对话教学表格式教学设计模板

\begin{tabular}{c|c|c|c|c|c|c}
\hline $\begin{array}{l}\text { 教学 } \\
\text { 模块 }\end{array}$ & $\begin{array}{c}\text { 知识、技 } \\
\text { 能、方法 }\end{array}$ & $\begin{array}{c}\text { 对话 } \\
\text { 形式 }\end{array}$ & $\begin{array}{c}\text { 学生 } \\
\text { 活动 }\end{array}$ & $\begin{array}{c}\text { 教师 } \\
\text { 活动 }\end{array}$ & $\begin{array}{c}\text { 设计 } \\
\text { 意图 }\end{array}$ & $\begin{array}{c}\text { 达成 } \\
\text { 目标 }\end{array}$ \\
\hline & & & & & & \\
& & & & & & \\
\hline
\end{tabular}

\section{3 基于对话的课堂环境设置}

\section{1 硬环境}

座位排列可根据不同的课型设计学生座位, 座位方式主 要有: 秧田式、圆桌式、小组式、马蹄式、蜂巢式、 $\mathrm{T}$ 型式、六边 形式、八边形式、弧形式等 ${ }^{[4]}$ 。本节课选择小组式。

\section{2 软环境}

营造爱、平等、谦虚、信任、希望、批判精神的课堂氛围。 


\section{4 基于对话的课堂教学过程}

模块一:基础知识复习(略); 模块二:实际应用 1 (略)。

探究一: 已知直线异侧两点 $A 、 B$, 在直线上求一点 $P$, 使 $P A+P B$ 最小。

模块三: 实际应用 2

学生活动: 探究二: 已知直线同侧两点 $A 、 B$, 在直线上求 一点 $P$,使 $P A+P B$ 最小。

若探究一中 $A 、 B$ 两镇的位置如下图所示, 原站应修在管 道 $L$ 上的什么地方, 才能使所用的输气管线最短呢?
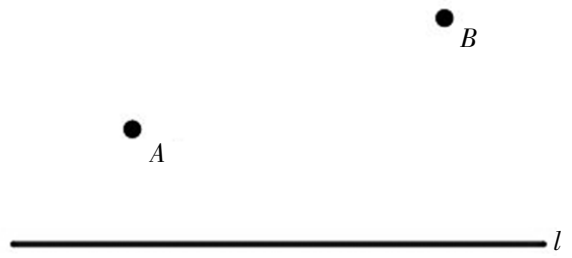

(同组讨论一动手操作一一展示成果一互动纠 错一归纳总结一验证结论; 作法由学生动手操作完成, 猜 想位置,计算尝试 (几何画板演示), 作图验证, 逻辑证明, 得出 结论, 验证过程由学生表达(书面、口头)

教师活动: 巡视指导一一展示成果——主导评价一反 馈矫正一一总结结论

活动过程: 师: 应用 2 是应用 1 的提高, 难点在于做辅助 线, 点 $P$ 是动点, 线段 $A P+B P$ 值最短, 即是让 $A P$ 转化为与它 相等的对称线段 $A P$, 也就转化成应用 1 了。生 6 : 知道这样 作, 但是不太明白为在什么这一点时线段 $A P+B P$ 值最短? 生 7 : 展示作图的的过程和证明的过程, 上讲台讲解证明的过程。

师评: 对称是线段之和最短问题求解的重要方法, 转化是 重要的数学思想, 问题的解决会让学生豁然开朗。

模块四: 课堂小结(略)

师:这节课我们学习了相关的知识和方法, 掌握了解答关 于“两线段之和最小”这种类型的问题的思考方法。生 9: 我们 会解答关于“异侧一线”或 “同侧一线”的问题。生 10 : 还知道 数学中转化的思想。

师评: 思维导图展示课堂小结, 便于学生理解记忆, 本模 块重在师生对话, 系统归纳数学知识、技能、方法, 使其融入到 学生的知识体系中,培养学生的学科核心素养。

\section{5 基于对话的课堂教学反思}

\section{1 对话教学案的设计}

备课时认真研读课标, 认真解读教材, 合理利用教学资 源, 恰当运用多媒体 ${ }^{[5]}$, 是设计这一堂课教学案的基础。首先
应确定教案的基本框架 (对话教学表格式教学案)和学案(每 个学生一份学习清单), 在每一个教学模块, 都运用对话教学 的教学形态来设计,模块一、模块二主要是生本对话形态的自 主学习,模块三主要是生生对话形态的合作学习,模块四是生 本对话形态的自主学习。根据教学内容选择对话的形式, 重点 在于学生活动和教师活动的设置、学生活动关注知识与生活、 数学情境的设计、数学方法的设计以及教师活动关注学法指 导、启发引领、合作参与、反馈矫正、激励评价的设计。

\section{2 课堂对话的环境设置}

(1)爱。对学生的爱是教学的基础, 教师发自内心对学生的 关爱能拉进师生间对话的距离, 全体学生会受到感染而积极 参与到师生、生生对话中。(2)平等。平等是对话的关键, 只有人 格上的平等, 才会有真正意义的对话发生, 教师要转变高高在 上的观念, 对学生存在的不足予以理解、宽容, 在生本对话过 程中给予学生引领、指导、分享, 在生生对话过程中组织、参 与、建议,在师生对话过程中给予学生启发、激励、唤醒、鼓舞。 (3)谦虚。谦虚是师生必备的品格, 也是做人的美德, 师生都要 以谦卑的态度对待人和事, 用无知的心态来学习。(4)信任。信 任是对话教学的先决条件, 如果不信任他人有做事的能力, 不 相信他人有创造力, 不相信他人有发展力, 对话就不会发生。 (5)希望。希望的反面是绝望,绝望是一种否定世界、逃避世界 的形式,如果对待进生不抱有任何希望, 对话教学同样不可能 产生。(6)批判思维。没有批判思维, 真正的对话就无从谈起, 就 无法真正理解世界的本质, 更谈不上改造世界, 只有在课堂上 进行批判性思维, 求同存异, 才能使对话双方获得最大视界的 融合。

\section{3 课堂对话教学过程}

在爱、平等、谦虚、信任的课堂氛围中, 点燃学习的激情, 培养学习的兴趣, 创造学习的希望, 使师生对同一个数学知 识、方法运用批判性思维展开认识, 求同存异, 达成共识, 达成 对话主体的最大融合, 使师生在共同学习的过程中体验成功 的乐趣。

\section{参考文献}

[1]中华人民共和国教育部.普通高中数学课程标准 (2017 年版) [S].

[2]李丽敏. 保罗. 弗莱雷. 对话式教学研究及对我国中小学教学改 革对启示[D].石家庄:河北师范大学,2008.

[3]李森,伍叶琴. 有效对话教学[M].福州:福建教育出版社,2012.

[4]张逢臣. 和谐高效思维对话一新课堂教学的实践探索 $[M]$. 北 京:教育科学出版社, 2011 .

[5]王向华.对话教育论纲[M].北京:教育科学出版社,2009. 